\title{
Association of industrial work schedules with development of metabolic syndrome, insulin resistance, and serum adipokine concentrations
}

\author{
Kalahasthi Ravibabu*®${ }^{\star}$, Surender Jakkam ${ }^{\circledR}$, Jamalpur Ravi Prakash ${ }^{\circledR}$, Vinay Kumar Adepu ${ }^{\circledR}$
}

\section{Abstract}

Background: Association of work schedule in industrial workers with the progression of metabolic syndrome, insulin resistance, and serum adipokine concentrations is incompletely explored.

Objective: To determine the association of work schedule with the progression of metabolic syndrome, insulin resistance, and adipokine concentrations in industrial workers.

Methods: In a cross-sectional study design of industrial workers we compared metabolic syndrome, insulin resistance, and adipokines concentration between workers in the day shift $(\mathrm{n}=52)$, rotational shift $(\mathrm{n}=21)$, and night $\operatorname{shift}(\mathrm{n}=15)$. The international Diabetes Federation criteria were used to diagnose metabolic syndrome. We used a homeostatic model assessment of insulin resistance (HOMA-IR). Serum insulin, leptin, and adiponectin concentrations were measured using enzyme-linked immunosorbent assays. Serum glucose, triglyceride, and high-density lipoprotein cholesterol (HDL-C) concentrations were monitored using Prietest clinical chemistry reagents.

Results: The proportional difference in metabolic syndrome $(0.31,95 \%$ confidence interval [CI] $0.036-0.587$, $P=0.026)$, median difference of leptin $(0.61,95 \% \mathrm{CI} 0.186-1.034, P=0.005)$, and leptin-to-adiponectin ratio (LAR; $0.45,95 \%$ CI $0.235-0.665, P<0.001)$ was significantly higher, and serum adiponectin was lower $(-2.00,95 \%$ CI -4.197 to $0.197, P=0.07)$ in the night-shift workers compared with that of day-shift workers. Among rotational-shift workers, the proportional difference between metabolic syndrome $(0.14,95 \% \mathrm{CI}-0.098$ to $0.378, P=0.25)$, median difference of leptin $(0.25,95 \% \mathrm{CI}-0.124$ to $0.624, P=0.19)$, and LAR $(0.09,95 \% \mathrm{CI}-0.099$ to $0.279, P=0.35)$ was higher, and serum adiponectin concentration was lower $(-0.73,95 \% \mathrm{CI}-2.660$ to $1.208, P=0.46)$ compared with that of day-shift workers; however, the altered differences were not significant. We observed a higher proportion of difference in HOMA-IR in shift workers (night and rotation) than in day-shift workers.

Conclusion: Night-shift workers are vulnerable to a higher risk of metabolic syndrome, HOMA-IR, and adipokine changes.

Keywords: metabolic syndrome; insulin resistance; adipokines; shift work schedule; occupational health

Shift work is that in which the working hours deviate from the standard daytime hours and is usually categorized into evening, night, early morning, and rotating shifts. The International
Agency for Research on Cancer (IARC) classifies shift work as having a probable carcinogenic effect [1]. Shift work disrupts the physiological rhythm of the suprachiasmatic nucleus

*Correspondence to: Kalahasthi Ravibabu, Regional Occupational Health Centre (Southern), Department of Biochemistry, Indian Council of Medical Research, ICMR Complex, Kannamangala Post, Poojanahalli Road, Devanahalli Taluk, Bengaluru 562110, Karnataka, India, email: ravibabu.k@gov.in

Department of Biochemistry, Regional Occupational Health Centre (Southern), Indian Council of Medical Research, ICMR Complex, Bengaluru 562110, Karnataka, India

D Open Access. $\odot 2021$ Ravibabu et al., published by Sciendo. (c) BY-NC-ND This work is licensed under the Creative Commons Attribution NonCommercial-NoDerivatives 4.0 License. 
network and leads to circadian rhythm dysregulation. In addition, hormonal imbalance has also been noted among shift workers. The hormones, i.e., cortisol, ghrelin, thyroid-stimulating hormone, growth hormone, insulin, leptin, and serotonin, are inclined to change [2]. Decreased insulin sensitivity, worsened glycemic changes, stress, increased body fat, hypertension, diabetes, and diseases of the heart and blood vessels are associated with shift work $[3,4]$.

In 2020, the total workforce of India was around 501 million, of which $41 \%$ was in agriculture, $26 \%$ was in industry, and the remainder were in the service sector [5]. The workers employed in industry suffer from various kinds of health problems, such as respiratory issues, swelling in legs or feet, skin allergies, headaches, general weakness, and fatigue [6]. Among industrial workers, a higher prevalence of metabolic syndrome, diabetes with impaired glucose tolerance, and hypertension are noted [7-9]. An association has been found between shift work in industry and being overweight, inflammation [10-12], hyperuricemia [13], cardiovascular health effects [14], fatigue [15], atherosclerosis [16], visual acuity [17], mental health outcomes [18], higher prevalence of erosive esophagitis [19], and coronary artery disease [20].

Individuals with metabolic syndrome had increased visceral tissue and disturbed adipokine secretion with low-grade chronic inflammation [21] and those with obesity have high plasma concentrations of insulin, homeostatic model assessment of insulin resistance (HOMA-IR), leptin, adiponectin, and leptin-to-adiponectin ratio (LAR) compared with those without obesity [22]. Gracia et al. [23] noted a positive relationship between serum leptin and metabolic syndrome in Mexican adult workers with obesity and insulin resistance. These adverse metabolic interactions can lead to a progression of hypertension and cardiovascular disease. Adiponectin is a crucial contributor to the development of metabolic syndrome and insulin resistance. Lower serum adiponectin levels are associated with a high risk of insulin resistance with increased glucose uptake, fatty acid oxidation, and glucose synthesis [24].

Leptin plays a vital role in attracting inflammatory cells. Leptin and adiponectin have opposing actions in subclinical inflammation. Leptin upregulates, while adiponectin downregulates, proinflammatory cytokines. LAR is considered as a newly identified biomarker for atherosclerotic plaque formation and insulin resistance. LAR may also be associated with a greater waist circumference [25]. Cripism et al. [26] noted a lower concentration of adiponectin in early morning shift workers. The interactions of leptin and adiponectin modulate the risk of type 2 diabetes mellitus, metabolic syndrome, and insulin resistance. LAR is a strong predictor for the risks of type 2 diabetes mellitus, metabolic syndrome, cardiovascular disease, and insulin resistance compared with measurements of leptin or adiponectin alone. It is a useful index for insulin resistance in clinical practice.

Studies examining the association between work schedule pattern (rotational, night and day shifts) and progression of medical health conditions among industrial workers are limited. In the present study, we investigated the association between work schedule pattern and progression of metabolic syndrome, insulin resistance, and serum adipokine concentrations in industrial workers.

\section{Methods}

Our institutional ethics committee approved the present study (approval No. 142, dated December 13, 2018). Written informed consent was obtained from each worker before they were enrolled in the study, which followed the principles outlined in the contemporary revision of the Declaration of Helsinki of 1964 (World Medical Association) incorporating the most recent (2013) and earlier amendments. The study design was in the form of a cross-sectional survey. The sample size was calculated using the inputs of $\alpha=0.05$, proportions of metabolic syndrome in night-shift workers $(\mathrm{P} 1=0.6)$ and day-shift workers $(\mathrm{P} 2=0.28)$, as reported in the present study with a power of $70 \%$. The sample size calculated for the present study was 75 (25 in each group), using a post hoc power analysis, although prospective power sample size calculation is widely accepted and strongly recommended. Dziak et al. [27] indicated that post hoc power analysis can be used if the data are presented in effect size, confidence interval (CI), or Bayesian posterior probabilities. In the present study, we used a post hoc power method to calculate the sample size. We enrolled 88 (day shift $\mathrm{n}=52$, rotation $\mathrm{n}=21$, and night $\mathrm{n}=15$ shift) industrial workers, who are occupied in the manufacturing of automobile bearing components and flavors.

The present survey was undertaken in 2019 in the State of Karnataka, India. Workers who had diabetes, hypertension, or blood lipid disorders with treatment, hypothyroidism, and inborn error metabolism were excluded. We included workers who were employed at the time of the study, were aged $\geq 18$ years, and without a history of chronic and systemic disease. The flow diagram of participants in the present study is shown in Figure 1. The diagnosis of metabolic syndrome among industrial workers was assessed using the criteria specified by the International Diabetes Federation (IDF) [28]. Insulin resistance among the industrial workers was assessed using the homeostasis model assessment (HOMA) method 


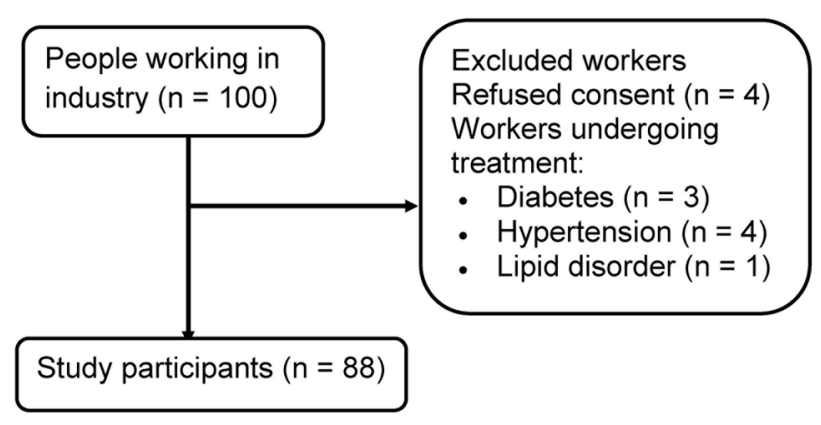

Figure 1. Flow diagram for participants.

described by Mathew et al. [29]. Serum insulin, adiponectin, and leptin concentrations in the workers were measured using enzyme-linked immunosorbent assays (ELISAs).

\section{Anthropometric dimensions and clinical examination}

Anthropometric dimensions and clinical evaluation data were collected from each worker using a questionnaire, which was prevalidated using a small sample population. The worker height was measured in centimeters using a tape and weight in kilograms with scales while they were in lightweight clothes and without shoes. The waist circumference was measured in accordance with the World Health Organization (WHO) diagnostic criteria for abdominal obesity. Systolic blood pressure (SBP) and diastolic blood pressure (DBP) were measured using a HEM-7112 monitor (Omron, Japan), while the worker was in a sitting posture after resting for $5 \mathrm{~min}$.

\section{Blood collection}

Whole blood $(4 \mathrm{~mL})$ was collected into vacutainer tubes with an easy clot activator (Labtech Disposables, India). The serum was separated by centrifuging for $10 \mathrm{~min}$ at $4,000 \mathrm{rpm}$ at $4{ }^{\circ} \mathrm{C}$. The resulting serum samples were used to measure glucose, triglyceride, high-density lipoprotein cholesterol (HDL-C), insulin, and adipokine concentrations.

\section{Serum glucose}

The fasting serum level of glucose was estimated using a Prietest glucose oxidase and peroxidase in vitro diagnostic kit based on a method developed by Trinder [30] (catalog No. GLUL 05 100; Robonik, India). The final product of 4-aminoantipyrine was measured at $505 \mathrm{~nm}$. The increased absorbance correlates with the glucose concentration in the sample. The detection limit of the method is $1 \mathrm{mg} / \mathrm{dL}$.

\section{Serum triglycerides}

Serum triglyceride concentrations were estimated using a Prietest in vitro diagnostic test kit based on a method developed by Fossati et al. [31] using the Trinder reaction [30] (catalog No. TRIG 05 10; Robonik). The quinoneimine end product was measured at $505 \mathrm{~nm}$. Its absorbance is proportional to the triglyceride present in the sample. The detection limit of the method is $1 \mathrm{mg} / \mathrm{dL}$.

\section{Serum HDL-C}

Serum HDL-C concentrations were estimated using a Prietest in vitro diagnostic test kit based on the phosphotungstic acid and magnesium ions precipitate method as described by Lopes et al. [32] (catalog No. HDC PPT 02 50; Robonik). In this approach, chylomicrons, very low-density lipoproteins, and low-density lipoproteins are precipitated by phosphotungstic acid and magnesium ions. After centrifugation, high-density lipoproteins (HDLs) are present in the supernatant. Cholesterol presented in this phase was measured using a Prietest in vitro diagnostic test kit based on an enzymatic, Trinder endpoint (catalog No. CHO 02 50; Robonik). The colorimetric indicator quinonimine is generated from 4-aminoantipyrine, phenol, and $\mathrm{H}_{2} \mathrm{O}_{2}$ under the catalytic action of peroxidase. The absorbance was measured at $510 \mathrm{~nm}$. The detection limit of the method is $4 \mathrm{mg} / \mathrm{dL}$.

\section{Serum insulin}

Serum insulin concentration was measured using a sandwich ELISA kit (catalog No. DKO076 Diametra, Italy). The lowest detectable insulin concentration is $0.25 \mu \mathrm{IU} / \mathrm{mL}$, and the detection range is $3-200 \mu \mathrm{IU} / \mathrm{mL}$.

\section{HOMA-IR}

HOMA-IR was calculated from fasting serum glucose and insulin concentrations in the participants using the method described by Mathew et al. [29] with the formula: serum insulin $(\mu \mathrm{IU} / \mathrm{mL}) \times$ serum glucose $(\mathrm{mg} / \mathrm{dL}) / 405$.

\section{Serum adiponectin}

Serum adiponectin concentration was measured using a sandwich ELISA kit (reference CAN-APN 5000; Diagnostics Biochem Canada). The limit of detection of the method is $0.06 \mathrm{ng} / \mathrm{mL}$ and the detection range is $0-50 \mathrm{ng} / \mathrm{mL}$. 


\section{Serum leptin}

Serum leptin concentration was measured using a sandwich ELISA kit (reference CAN-L 4260; Diagnostics Biochem Canada). The limit detection of the method is $0.50 \mathrm{ng} / \mathrm{mL}$, and the detection range is up to $100 \mathrm{ng} / \mathrm{mL}$.

\section{LAR}

The LAR calculated value was from the serum leptin and serum adiponectin concentrations of individual subjects.

\section{Statistical analysis}

IBM SPSS Statistics for Windows (version 26) was used to analyze the data. The data are presented as mean \pm standard deviation, proportion, and proportional differences with $95 \%$ CI, median, and the median difference with $95 \%$ CI. The proportional difference with $95 \% \mathrm{CI}$ of metabolic syndrome and HOMA-IR in different shift workers was compared with a 2-sample Z-test sample proportions using Epitools software. The median difference with $95 \%$ CI of adipokines among different shift workers was compared using quantile regression with 50th percentiles. $P<0.05$ was considered as significant.

\section{Results}

The diagnosis of metabolic syndrome based on the IDF criteria is presented in Table 1. Waist circumference risk and the presence of 2 risk factors of elevated serum triglyceride, blood pressure (SBP or DBP), serum glucose, and low levels of HDL-C were considered as metabolic syndrome.

The details of the anthropometric and metabolic components of industrial workers according to work schedule patterns are presented in Table 2. The details of age, height, weight, and body mass index (BMI) in workers are considered as anthropometrics. The particulars of SBP, DBP, serum glucose, triglyceride, HDL-C, and insulin were considered as metabolic components. The normality of parameters was assessed using a Shapiro-Wilk test. Height, weight, BMI, and waist circumference were found normally distributed and were compared between shift workers using a parametric one-way analysis of variance (ANOVA) with a least significant difference (LSD) post hoc test. Age, SBP, DBP, glucose, HDL-C, and insulin level were not normally distributed and were compared between shift workers using a nonparametric Kruskal-Wallis test. The results of both analyses showed no significant association between any variable tested and shift work schedule.
Table 1. International Diabetes Foundation definition of metabolic syndrome

\begin{tabular}{ll}
\hline Parameters & Defining level \\
\hline Waist circumference & Male $\geq 90 \mathrm{~cm}$ \\
& Female $\geq 80 \mathrm{~cm}$ \\
Serum triglyceride & $\geq 150 \mathrm{mg} / \mathrm{dL}$ \\
Serum HDL-C & $<40 \mathrm{mg} / \mathrm{dL}$ in male \\
Blood pressure (SBP or DBP) & $<50 \mathrm{mg} / \mathrm{dL}$ in female \\
& SBP $\geq 130 \mathrm{~mm} \mathrm{Hg}$ \\
Fasting serum glucose (mg/dL) & or \\
\hline
\end{tabular}

Diagnosis of metabolic syndrome $=\mathrm{WC}+$ any 2 criteria

DBP, diastolic blood pressure; HDL-C, high-density lipoprotein cholesterol; SBP, systolic blood pressure; WC, waist circumference.

The proportion difference with $95 \%$ CI of metabolic syndrome and HOMA-IR among industrial workers according to their work schedule pattern is presented in Table 3. The highest proportion of metabolic syndrome was noted in night-shift workers $(0.60)$ followed by rotational $(0.43)$ and then day-shift workers (0.29). The proportional difference in metabolic syndrome among night-shift workers was significantly increased $(P=0.026)$ when compared with that of day-shift workers. No significant difference was noted in the comparison between the rotational shift and day-shift workers $(P=0.25)$.

The normal and abnormal proportion of HOMA-IR among workers was analyzed using the cutoff value described by Singh et al. [33]. The highest proportion of abnormal HOMA-IR was noted in the night-shift workers $(0.47)$, followed by rotational shift $(0.43)$ and then day-shift workers $(0.33)$. No significant difference was noted in the comparison between night-shift workers $(P=0.32)$ and day-shift workers or rotational shift workers $(P=0.41)$.

Quantile regression at the 50th percentile (median regression) of adipokines among industrial workers according to work schedule pattern is presented in Table 4. Because the data were not found to be normally distributed, the concentration of adipokines among different shift workers was compared using quantile regression with 50th percentile. In this model, the levels of adipokines (leptin, adiponectin, and LAR) were used as dependent variables and work schedule patterns (night shift $=1$, rotation $=2$, and day shift $=3$ ) were used as covariates. The results of this model provide median, median difference, and their $95 \% \mathrm{CI}$. The highest median serum leptin concentration was noted in night-shift workers $(1.64 \mathrm{ng} / \mathrm{mL})$ followed by rotational shift $(1.28 \mathrm{ng} / \mathrm{mL})$ and day-shift workers $(1.03 \mathrm{ng} / \mathrm{mL})$. The median difference in serum leptin (0.61) in night-shift 
workers was significantly $(P=0.005)$ altered. The median difference between rotational and day workers was not significant $(P=0.19)$. The lowest median concentration of serum adiponectin was noted in night-shift workers $(2.51 \mathrm{ng} / \mathrm{mL})$ followed by rotational shift $(3.78 \mathrm{ng} / \mathrm{mL})$ and day-shift workers $(4.51 \mathrm{ng} \mathrm{mL})$. The median difference in

Table 2. Anthropometric and metabolic variables of industrial workers according to work schedule

\begin{tabular}{|c|c|c|c|c|}
\hline Parameters & Day shift $(n=52)$ & Rotation shift $(n=21)$ & Night shift $(n=15)$ & $P$ \\
\hline Age (years) & $33.4 \pm 8.8$ & $35.3 \pm 11.3$ & $32.2 \pm 9.4$ & 0.53 \\
\hline Height $(\mathrm{cm})$ & $161.4 \pm 9.1$ & $164.0 \pm 7.7$ & $162.7 \pm 8.9$ & 0.51 \\
\hline Weight (kg) & $61.8 \pm 11.5$ & $64.2 \pm 10.7$ & $64.4 \pm 9.9$ & 0.60 \\
\hline $\mathrm{BMI}\left(\mathrm{kg} / \mathrm{m}^{2}\right)$ & $23.7 \pm 4.0$ & $24.0 \pm 3.8$ & $24.3 \pm 3.3$ & 0.86 \\
\hline Waist circumference $(\mathrm{cm})$ & $83.8 \pm 9.1$ & $86.9 \pm 9.8$ & $87.4 \pm 12.1$ & 0.31 \\
\hline $\mathrm{SBP}(\mathrm{mm} \mathrm{Hg})$ & $122.8 \pm 15.9$ & $128.3 \pm 17.9$ & $124.5 \pm 20.9$ & 0.43 \\
\hline $\mathrm{DBP}(\mathrm{mm} \mathrm{Hg})$ & $74.4 \pm 11.5$ & $72.6 \pm 8.9$ & $77.4 \pm 16.4$ & 0.57 \\
\hline Glucose (mg/dL) & $89.0 \pm 17.7$ & $106.8 \pm 56.1$ & $85.8 \pm 25.7$ & 0.27 \\
\hline Triglyceride (mg/dL) & $143 \pm 71$ & $165 \pm 108$ & $195 \pm 128$ & 0.34 \\
\hline $\mathrm{HDL}-\mathrm{C}(\mathrm{mg} / \mathrm{dL})$ & $36.1 \pm 8.3$ & $33.9 \pm 7.2$ & $33.5 \pm 9.3$ & 0.55 \\
\hline Insulin ( $\mu \mathrm{IU} / \mathrm{ml})$ & $11.8 \pm 10.7$ & $16.2 \pm 13.9$ & $15.4 \pm 15.4$ & 0.47 \\
\hline
\end{tabular}

BMI, body mass index; DBP, diastolic blood pressure; HDL-C, high-density lipoprotein cholesterol; SBP, systolic blood pressure.

Table 3. Proportional difference and $95 \% \mathrm{Cl}$ of metabolic syndrome and HOMA-IR in industrial workers according to work schedule

\begin{tabular}{|c|c|c|c|c|c|}
\hline Metabolic disorder & Comparison & Proportion difference & $\mathbf{9 5 \%} \mathrm{Cl}$ of difference & $Z$ & $P$ \\
\hline \multirow[t]{4}{*}{ Metabolic syndrome } & Night vs. day shift & $0.60-0.29$ & 0.036 to 0.587 & 2.2 & $0.026^{*}$ \\
\hline & & 0.31 & & & \\
\hline & Rotation vs. day shift & $0.43-0.29$ & -0.098 to 0.378 & 1.2 & 0.25 \\
\hline & & 0.14 & & & \\
\hline \multirow[t]{4}{*}{ HOMA-IR } & Night vs. day shift & $0.47-0.33$ & -0.135 to 0.415 & 1.0 & 0.32 \\
\hline & & 0.14 & & & \\
\hline & Rotation vs. day shift & $0.43-0.33$ & -0.140 to 0.344 & 0.8 & 0.41 \\
\hline & & 0.10 & & & \\
\hline
\end{tabular}

$\mathrm{Cl}$, confidence interval; HOMA-IR, homeostatic model assessment of insulin resistance.

${ }^{*} P<0.05$.

Table 4. Median difference and $95 \% \mathrm{Cl}$ of serum adipokine levels in industrial workers according to work schedule

\begin{tabular}{|c|c|c|c|c|}
\hline Adipokine & Comparison & Median difference & $95 \% \mathrm{Cl}$ of difference & $P$ \\
\hline \multirow[t]{4}{*}{ Leptin } & Night vs. day shift & $1.64-1.03$ & 0.186 to 1.034 & $0.005^{* *}$ \\
\hline & & 0.61 & & \\
\hline & Rotation vs. day shift & $1.28-1.03$ & -0.124 to 0.624 & 0.19 \\
\hline & & 0.25 & & \\
\hline \multirow[t]{4}{*}{ Adiponectin } & Night vs. day shift & $2.51-4.51$ & -4.197 to 0.197 & 0.07 \\
\hline & & -2.00 & & \\
\hline & Rotation vs. day shift & $3.78-4.51$ & -2.660 to 1.208 & 0.46 \\
\hline & & -0.73 & & \\
\hline \multirow[t]{4}{*}{ LAR } & Night vs. day shift & $0.67-0.22$ & 0.235 to 0.665 & $<0.001^{* *}$ \\
\hline & & 0.45 & & \\
\hline & Rotation vs. day shift & $0.31-0.22$ & -0.099 to 0.279 & 0.35 \\
\hline & & 0.09 & & \\
\hline
\end{tabular}

$\mathrm{Cl}$, confidence interval; $\mathrm{LAR}$, leptin-to-adiponectin ratio.

${ }^{*} P<0.01$. 
serum adiponectin in night-shift workers $(-2.00, P=0.07)$ and rotational shift $(-0.73, P=0.46)$ was not decreased significantly. The highest median LAR median was found in night-shift workers $(0.67)$ followed by rotational shift $(0.31)$ and then day-shift workers $(0.22)$. The median difference in LAR (0.45) in the night-shift workers was increased significantly $(P<0.001)$ compared with day-shift workers. The median difference in LAR (0.09) between rotational shift workers and day-shift workers was not significant $(P=0.35)$.

\section{Discussion}

The present study evaluated the association between work schedule pattern (day, rotation, and night shift) and progression of metabolic syndrome, HOMA-IR, and serum adipokine concentrations (leptin, adiponectin, and LAR) among industrial workers. Sadek et al. [34] reported a $72.2 \%$ metabolic syndrome in night-shift workers; in the present study, we reported $60 \%$ of metabolic syndrome in night-shift workers; while Pietroiusti et al. [35] reported $9 \%$ of cumulative incidence of metabolic syndrome among night-shift workers. In the present study, we found a significant difference in the proportion of night-shift workers with metabolic syndrome compared with day shift workers. Lin et al. [36] reported an association between the progression of metabolic syndrome and day-night rotation shift. In the present study, we found an increased proportion of rotational shift workers with metabolic syndrome. Oh and Yim [37] reported no significant differences in metabolic syndrome among workers on 3 -shift rotation ( $8 \mathrm{~h}$ ) compared with day-shift workers. In the present study, we found no significant difference when comparing the proportion of rotational $(8 \mathrm{~h})$ and day-shift workers with metabolic syndrome. Working shift and progression of metabolic syndrome has been shown as epidemiological evidence of physiopathological mechanisms [38].

Several studies have reported that shift work is associated with various kinds of metabolic disorders, e.g., obesity, metabolic syndrome, diabetes, hypertension, insulin resistance, and cardiovascular disease [39-41] and promotes dyslipidemia [42], hormonal appetite control [43], alters glucose metabolism [44], and electrocardiogram QTc interval [45]. The biological differences between day-shift and night-shift workers include misalignments of rhythmic physiological systems, hormonal imbalance (melatonin and cortisol), activation of the autonomic nervous system, inflammation, higher level of oxidative stress and lower levels of antioxidants, exposure to artificial light at night, sleep deprivation with depressive symptoms, and reduced brain volumes in the gray matter of postcentral gyrus, right paracentral lobule, and left superior temporal gyrus [46-49].

HOMA is a method used to assess insulin resistance and $\beta$-cell function using fasting serum glucose and insulin concentration [29]. We assessed insulin resistance in the various shift workers. The normal and abnormal proportions of HOMA-IR between different shift workers were determined using a cutoff $<2.5$ and $>2.5$. We found the highest proportion of abnormal HOMA-IR in night-shift workers, succeeded by rotational shift and day-shift workers, and this was consistent with the findings noted in healthcare shift workers [50], rotational night-shift healthcare workers [51], and policemen working in shifts [52]. Esquirol et al. [53] compared the HOMA-IR in shift workers and day workers and found no noteworthy alteration. In the present study, we observed an increased HOMA-IR in shift workers, but the difference was not significant.

Individuals with a risk of metabolic syndrome, insulin resistance, and obesity have associated altered adipokine secretion, accompanied by low-grade inflammation. This state gives rise to diabetes, hypertension, and progression of cardiovascular disease. In the present study, we assessed adipokines in industrial workers working in different shifts. Crispim et al. reported reduced adiponectin concentration and increased leptin concentration in early morning shift workers compared with daytime workers [26, 43]. In the present study, we observed lower levels of adiponectin and higher levels of leptin in night-shift workers compared with day-shift workers. In contrast to higher serum leptin levels and LAR, we found significantly lower serum adiponectin levels in night-shift workers. Mota et al. [54] reported excessive sleep in the daytime in those with a lower serum leptin concentration. Schiavo-Cardozo et al. [55] reported that altered adipokines are associated with behavioral changes in diet, sleep, increased adiposity, and linked metabolic alterations.

Our study limitations include lack of evaluation of workers for their physical activity, nutritional status, diet, energy expenditure, and food consumption recordings. Another limitation is the sample size derived in the present study using power calculation, which is related to the equal size in the 3 groups: day, rotation, and night. The sample size in the rotational and night-shift groups was found to be inadequate. We recommend comparing groups with an adequate sample size and the inclusion of lifestyle factors in future studies. 


\section{Conclusions}

Night-shift workers are vulnerable to a higher risk of metabolic syndrome, insulin resistance, and serum adipokine level alterations. Interventional approaches are needed to minimize the metabolic disorders arising from shift work.

Author contributions: KR and JS contributed substantially to the conception and design of the study. All the authors contributed to curating the data, and its analysis and interpretation. All the authors contributed substantially to drafting the manuscript, and KR, JR, and AV revised it critically for important intellectual content. All the authors approved the final version submitted for publication and take responsibility for the statements made in the published article.

Acknowledgments: Funding for this study was provided by the Indian Council for Medical Research and the National Institute of Occupational Health.

Conflict of interest statement: The authors have each completed and submitted an International Committee of Medical Journal Editors Disclosure Form for Potential Conflicts of Interest. None of the authors has any potential of actual conflict of interest to disclose.

Data sharing statement: Statistical summaries of data generated and analyzed for the present article are included in the published article. Further details are available from the corresponding author on reasonable request after deidentification from any participant whose data are included in this report.

\section{References}

[1] Erren TC, Morfeld P, Groß JV, Wild U, Lewis P. IARC 2019: "Night shift work" is probably carcinogenic: what about disturbed chronobiology in all walks of life? J Occup Med Toxicol. 2019; 14:29. doi: 10.1186/s12995-019-0249-6

[2] Kulkarni K, Schow M, Shubrook JH. Shift workers at risk for metabolic syndrome. J Am Osteopath Assoc. 2020; 120:107-17.

[3] Ulhôa MA, Marqueze EC, Burgos LGA, Moreno CR. Shift work and endocrine disorders. Int J Endocrinol. 2015; 2015:826249. doi: $10.1155 / 2015 / 826249$

[4] Di Lorenzo L, De Pergola G, Zocchetti C, L'Abbate N, Basso A, Pannacciulli N, et al. Effect of shift work on body mass index: results of a study performed in 319 glucose-tolerant men working in a Southern Italian industry. Int J Obes Relat Metab Disord. 2003; 27:1353-8.

[5] Labour force, total-India. Derived using data from the International Labour Organization, ILOSTAT database [internet]. Geneva: ILO Department of Statistics of the United Nations;
Copyright (๑) International Labour Organization 2020 [cited 2020 June 21]. Available from: https://ilostat.ilo.org/data/country-profiles

[6] Varma N, Singh MM. Health related problems in industrial workers due environmental hazards. Int J Sci Tech Manag. 2015; 4(7):194-202.

[7] Baghshini MR, Nikbakht-Jam I, Mohaddes-Ardabili H, Pasdar A, Avan A, Tayefi M, et al. Higher prevalence of metabolic syndrome among male employees of a gas refinery than in their counterparts in nonindustrial environments. Asian Biomed (Rev Res News). 2017; 11:227-34

[8] Mini GK, Sarma PS, Thankappan KR. Overweight, the major determinant of metabolic syndrome among industrial workers in Kerala, India: results of a cross-sectional study. Diabetes Metab Syndr. 2019; 13:3025-30.

[9] Jagannathan R, Nanditha A, Sundaram S, Simon M, Shetty AS, Snehalatha C, et al. Screening among male industrial workers in India shows high prevalence of impaired glucose tolerance, undetected diabetes and cardiovascular risk clustering. J Assoc Physicians India. 2014; 62:312-5.

[10] Rabanipour N, Roohafza H, Feizi A, Amani Tirani S, Sarrafzadegan $\mathrm{N}$. Association between shift work and obesity in a large sample of Iranian steel industry workers. Arh Hig Rada Toksikol. 2019; 70:194-200.

[11] Sun M, Feng W, Wang F, Li P, Li Z, Li M, et al. Meta-analysis on shift work and risks of specific obesity types. Obes Rev. 2018; 19:28-40.

[12] Kim S-W, Jang E-C, Kwon S-C, Han W, Kang M-S, Nam Y-H, Lee Y-J. Night shift work and inflammatory markers in male workers aged 20-39 in a display manufacturing company. Ann Occup Environ Med. 2016; 28:48. doi: 10.1186/s40557-016-0135-y.

[13] de Pedro Jiménez D, de Diego Cordero R, Romero-Saldaña $\mathrm{M}$, Verástegui C. Hiperuricemia y menor actividad física en trabajadores a turnos: estudio transversal en una industria química Española [Hyperuricemia in shift workers: a cross-sectional study in a Spanish chemical factory.] Rev Esp Salud Publica. 2020; 94:e202004028. [in Spanish, English abstract]

[14] Lunde L-K, Skare Ø, Mamen A, Sirnes PA, Aass HCD, Øvstebø R, et al. Cardiovascular health effects of shift work with long working hours and night shifts: study protocol for a three-year prospective follow-up study on industrial workers. Int J Environ Res Public Health. 2020; 17:589. doi: 10.3390/ijerph17020589

[15] Riethmeister V, Matthews RW, Dawson D, de Boer MR, Brouwer S, Bültmann U. Time-of-day and days-on-shift predict increased fatigue over two-week offshore day-shifts. Appl Ergon. 2019; 78:157-63.

[16] Skogstad M, Mamen A, Lunde L-K, Ulvestad B, Matre D, Aass HCD, et al. Shift work including night work and long working hours in industrial plants increases the risk of atherosclerosis. Int J Environ Res Public Health. 2019; 16:521. doi: 10.3390/ijerph16030521

[17] Lin Y-C, Ho K-J. Night-shift work and risk of compromised visual acuity among the workers in an electronics manufacturing company. Int J Occup Med Environ Health. 2018; 31:71-9.

[18] Wyse CA, Celis Morales CA, Graham N, Fan Y, Ward J, Curtis AM, et al. Adverse metabolic and mental health outcomes associated with shiftwork in a population-based study of 277,168 workers in UK biobank. Ann Med. 2017; 49:411-20.

[19] Chung TH, Lee J, Kim MC. Impact of night-shift work on the prevalence of erosive esophagitis in shipyard male workers. Int Arch Occup Environ Health. 2016; 89:961-6. 
[20] Kang W-Y, Park W-J, Jang K-H, Kim S-H, Gwon D-H, Lim H-M, et al. Coronary artery atherosclerosis associated with shift work in chemical plant workers by using coronary CT angiography. Occup Environ Med. 2016; 73:501-5.

[21] Zhang Y, Yang P, Cui R, Zhang M, Li H, Qian C, et al. Eosinophils reduce chronic inflammation in adipose tissue by secreting Th2 cytokines and promoting M2 macrophages polarization. Int J Endocrinol. 2015; 2015:565760. doi: 10.1155/2015/565760

[22] Satoh N, Naruse M, Usui T, Tagami T, Suganami T, Yamada K, et al. Leptin-to-adiponectin ratio as a potential atherogenic index in obese type 2 diabetic patients. Diabetes Care. 2004;27:2488-90.

[23] García-Jiménez S, Bernal Fernández G, Martínez Salazar MF, Monroy Noyola A, Toledano Jaimes C, Meneses Acosta A, et al. Serum leptin is associated with metabolic syndrome in obese Mexican subjects. J Clin Lab Anal. 2015; 29:5-9.

[24] Kadowaki T, Yamauchi T. Adiponectin and adiponectin receptors. Endocr Rev. 2005; 26:439-51.

[25] López-Jaramillo P, Gómez-Arbeláez D, López-López J, López-López C, Martínez-Ortega J, Gómez-Rodríguez A, TrianaCubillos S. The role of leptin/adiponectin ratio in metabolic syndrome and diabetes. Horm Mol Biol Clin Investig. 2014; 18:37-45.

[26] Crispim CA, Padilha HG, Zimberg IZ, Waterhouse J, Dattilo M, Tufik S, de Mello MT. Adipokine levels are altered by shiftwork: a preliminary study. Chronobiol Int. 2012; 29:587-94.

[27] Dziak JJ, Dierker LC, Abar B. The Interpretation of Statistical Power after the Data have been Gathered. Curr Psychol. 2020;39:870-7.

[28] International Diabetes Federation: The IDF consensus worldwide definition of the metabolic syndrome. [internet]. 2006 [cited 2020 Jul 29]. Available from: https://www.idf.org/our-activities/ advocacy-awareness/resources-and-tools/60:idfconsensus-worldwidedefinitionof-the-metabolic-syndrome.html

[29] Matthews DR, Hosker JP, Rudenski AS, Naylor BA, Treacher DF Turner RC. Homeostasis model assessment: insulin resistance and $\beta$-cell function from fasting plasma glucose and insulin concentrations in man. Diabetologia. 1985; 28:412-9.

[30] Trinder P. Determination of blood glucose using an oxidaseperoxidase system with a non-carcinogenic chromogen. J Clin Pathol. 1969; 22:158-61.

[31] Fossati P, Prencipe L. Serum triglycerides determined colorimetrically with an enzyme that produces hydrogen peroxide. Clin Chem. 1982; 28:2077-80.

[32] Lopes-Virella MF, Stone P, Ellis S, Colwell JA. Cholesterol determination in high-density lipoproteins separated by three different methods. Clin Chem 1977; 23:882-4.

[33] Singh Y, Garg MK, Tandon N, Marwaha RK. A study of insulin resistance by HOMA-IR and its cut-off value to identify metabolic syndrome in urban Indian adolescents. J Clin Res Pediatr Endocrinol. 2013; 5:245-51

[34] Sadek RR, Zayet HS, Refaat TM, Abdelmageed AS, Kamel SM. Metabolic syndrome among shift workers in Minia mills, Egypt. J Crit Rev. 2020; 7:2330-8.

[35] Pietroiusti A, Neri A, Somma G, Coppeta L, Iavicoli I, Bergamaschi A, Magrini A. Incidence of metabolic syndrome among night-shift healthcare workers. Occup Environ Med. 2010; 67:54-7.

[36] Lin Y-C, Hsiao T-J, Chen P-C. Persistent rotating shift-work exposure accelerates development of metabolic syndrome among middle-aged female employees: a five-year follow-up. Chronobiol Int. 2009; 26:740-55.

[37] Oh JI, Yim HW. Association between rotating night shift work and metabolic syndrome in Korean workers: differences between 8-hour and 12-hour rotating shift work. Ind Health. 2018; 56:40-8.

[38] Ruxandra OM, Agripina R, Ileana I, Anton AI, Adela B, Camelia $\mathrm{C}$, et al. Working in shifts and the metabolic syndrome: epidemiological evidence and physiopathological mechanisms. ARS Medica Tomitana. 2018; 24:144-51.

[39] Brum MC, Filho FF, Schnorr CC, Bottega GB, Rodrigues TC. Shift work and its association with metabolic disorders. Diabetol Metab Syndr. 2015; 7:45. doi: 10.1186/s13098-015-0041-4

[40] Abu Farha R, Alefishat E. Shift work and the risk of cardiovascular diseases and metabolic syndrome among Jordanian employees. Oman Med J. 2018; 33:235-42.

[41] Tucker P, Marquié J-C, Folkard S, Ansiau D, Esquirol Y. Shiftwork and metabolic dysfunction. Chronobiol Int. 2012; 29:549-55.

[42] Dutheil F, Baker JS, Mermillod M, De Cesare M, Vidal A, Moustafa F, et al. Shift work, and particularly permanent night shifts, promote dyslipidaemia: a systematic review and meta-analysis. Atherosclerosis. 2020; 313:156-69.

[43] Crispim CA, Waterhouse J, Dâmaso AR, Zimberg IZ, Padilha HG, Oyama LM, et al. Hormonal appetite control is altered by shift work: a preliminary study. Metabolism. 2011; 60:1726-35.

[44] Sharma A, Laurenti MC, Dalla Man C, Varghese RT, Cobelli C, Rizza RA, et al Glucose metabolism during rotational shift-work in healthcare workers. Diabetologia. 2017; 60:1483-90.

[45] Campagna M, Locci E, Piras R, Noto A, Lecca LI, Pilia I, et al. Metabolomics patterns associated to QTc interval in shift workers: an explorative analysis. Biomarkers. 2016; 21:607-13.

[46] Mohd Azmi NAS, Juliana N, Mohd Fahmi Teng NI, Azmani S, Das S, Effendy N. Consequences of circadian disruption in shift workers on chrononutrition and their psychosocial well-being. Int J Environ Res Public Health. 2020; 17:2043. doi: 10.3390/ ijerph17062043

[47] Touitou Y, Reinberg A, Touitou D. Association between light at night, melatonin secretion, sleep deprivation, and the internal clock: health impacts and mechanisms of circadian disruption. Life Sci. 2017; 173:94-106.

[48] Teixeira KRC, Dos Santos CP, de Medeiros LA, Mendes JA, Cunha TM, De Angelis K, et al. Night workers have lower levels of antioxidant defenses and higher levels of oxidative stress damage when compared to day workers. Sci Rep. 2019; 9:4455. doi: 10.1038/ s41598-019-40989-6

[49] Park C-H, Bang M, Ahn KJ, Kim WJ, Shin N-Y. Sleep disturbancerelated depressive symptom and brain volume reduction in shift-working nurses. Sci Rep. 2020; 10:9100. doi: 10.1038/s41598020-66066-x

[50] Ledda C, Ciná D, Matera S, Mucci N, Bracci M, Rapisarda V. High HOMA-IR index in healthcare shift workers. Medicina (Kaunas). 2019; 55:186. doi: 10.3390/medicina55050186

[51] Kiranmala K, Aslam M, Mishra BK, Jhamb R, Madhu SV. Association of postprandial triglyceride responses with insulin resistance among rotational night shift healthcare workers. Exp Physiol. 2019; 104:819-25.

[52] Demir I, Toker A, Zengin S, Laloglu E, Aksoy H. Oxidative stress and insulin resistance in policemen working shifts. Int Arch Occup Environ Health. 2016; 89:407-12. 
[53] Esquirol Y, Bongard V, Ferrieres J, Verdier H, Perret B. Shiftwork and higher pancreatic secretion: early detection of an intermediate state of insulin resistance? Chronobiol Int. 2012; 29:1258-66.

[54] Mota MC, Waterhouse J, De-Souza DA, Rossato LT, Silva CM, Araújo MBJ, et al. Sleep pattern is associated with adipokine levels and nutritional markers in resident physicians. Chronobiol Int. 2014; 31:1130-8.

[55] Schiavo-Cardozo D, Lima MMO, Pareja JC, Geloneze B. Appetiteregulating hormones from the upper gut: disrupted control of xenin and ghrelin in night workers. Clin Endocrinol (Oxf). 2013; 79:807-11. 